\section{Resonance in the Chloroacetic Acids}

IN addition to heat data, internuclear distances, and electric dipole moments, dissociation constants are now being used to determine whether or not possible valence bond structures contribute to the actual state of a molecule ${ }^{1}$.

It is suggested that the dissociation constants of the three chloroacetic acids furnish such information. These acids present an interesting problem. The relevant data ${ }^{2,3}$ are : $\mathrm{CH}_{3} \mathrm{COOH}, K=1.7 \times 10^{-5}$; $\mathrm{CH}_{2} \mathrm{ClCOOH}, K=1.4 \times 10^{-3} ; \mathrm{CHCl}_{2} \mathrm{CO} \mathrm{OH}, K=$ $5 \cdot 1 \times 10^{-2} ; \mathrm{CCl}_{3} \mathrm{COOH}, K=1 \cdot 2$. Now monochloroacetic acid has a dissociation constant about eighty times that of the unsubstituted acid, the reasonable explanation being that the strong dipole $\stackrel{+}{\mathrm{C}}-\overline{\mathrm{Cl}}\left(\mu_{\mathrm{Cl}}=1.5 \mathrm{D}\right)$ has been substituted for the weak dipole $\stackrel{+}{\dot{H}}-\overline{\mathrm{C}}\left(\mu_{\mathrm{H}}=0.4 D\right)$. Di- and trisubstitution, however, lead to dissociation constants 3,000 and 100,000 times that of the parent acid.

Let $\mu_{\mathrm{Cl}}$ be the moment of the $\mathrm{C}-\mathrm{Cl}$ link in chloroacetic acid. The resultant moment $\left(\mu_{R}\right)$ of the two C. Cl links in dichloroacetic acid is $2 \mu_{\mathrm{Cl}} \cos \theta / 2$, and for the three $\mathrm{C}-\mathrm{Cl}$ links in trichloroacetic acid it is $\mu_{\mathrm{Cl}}(6 \cos \theta+3)^{1 / 2}, \theta$ being the tetrahedral angle, and neglecting dipole interaction. It is clear that no functional relationship can be traced between $\mu_{R}$ and $K$, since the $\mu_{R}$ 's are all of the same order of magnitude, being in the ratios $1: 1 \cdot 2: 1$. It is also probable that dipole interaction reduces the resultant moments of the dichloro and trichloro groups, as shown by the dipole moments of methyl chloride, methylene chloride, and chloroform*

Some other factor must thus enter and succeed in strongly enhancing the dissociation constants of the di- and tri-substituted acids. It is suggested that this additional factor is resonance, which preferentially stabilizes the ionic forms. In the mono-substituted acid, the inductive effect of the $\mathrm{C}-\mathrm{Cl}$ dipole is the enhancing influence, but in the case of the disubstituted compound, four conjugated structures of equal energy of the type<smiles>O=C([O-])[C+]=[Cl+2]</smiles>

contribute to the actual state of the ion, the energy of resonance effecting stabilization. With trichloroacetic acid, twelve structures of the type<smiles>O=C([O-])[C+](Cl)Cl</smiles>

contribute, quantum mechanics leading also to the conclusion that each $\mathrm{C}-\mathrm{Cl}$ bond length will be equal to and approach the double bond value ${ }^{5}$. Because of the separation of charge, these structures would not be expected to be as stable as the normal structures, but a linear relation does exist between $\log n$ and $\log K$ for the three chloro acids with $n=2,6$, and 14. It may be mentioned that electron diffraction investigations have established the facts ${ }^{8}$ that the
$\mathrm{C}-\mathrm{F}$ bond distance in methyl fluoride is $1.42 \mathrm{~A}$., whereas it is $1.36 \mathrm{~A}$. in methylene fluoride, indicating the existence of structures of the type now postulated.

35 Grand Avenue,

H. O. JENKINS.

\section{Ely, Cardiff.}

March 1.

1 Jenkins, H. O., NATURE, 145, 149 (1940).

'Dippy, J. F. J., Chem. Rev., 25, 204 (1939).

s Cohen, "Organic Chemistry", Part 1, p. 341 (Arnold)

- Sutton, L. E., and Brockway, L. O., J. Amer. Chem. Soc., 57, 473 (1935).

- See numerous publications of Linus Pauling.

${ }^{6}$ Brockway, L. O., J. Phys. Chem., 41, 747 (1937).

\section{History of the Vacuum Flask}

SIR WILLIAM BragG, in the brief account of his lectures on Dewar's research published in NATURE of March 16, mentions that vacuum vessels were made in the early days by C. E. Muller, who was a German glassblower settled in London. Though this is undoubtedly correct so far as it goes, I think that it may leave the wrong impression that Muller made the first vacuum vessels. Such an impression would be unjust to the memory of Dewar's assistant, R. N. Lennox, who actually made the first vessels. They were pointed out to me by my father a few weeks afterwards, on Lennox's bench as Lennox's work. My father's assistant, George Gordon, who had seen Lennox making them, showed me the method which he had seen Lennox use, making a small cylindrical vessel as a demonstration for me. To make spherical vessels was rather beyond Gordon's skill, and later he got Lennox to show me this. The early vessels used by Dewar for some time were of Lennox's make, and if I am not mistaken, some of them are still preserved at the Royal Institution. I should recognize them without doubt. It is likely that Muller was the first to make such vessels outside the Royal Institution, but I do not think that he had arrived in London when Lennox first made them. I was in the habit of frequenting his shop as soon as I learnt of its existence.

Terling Place,
Chelmsford.
March 27.

RAYLeigh.

\section{Aurora and Magnetic Storm of March 24-25}

THE aurora and great magnetic storm of March 24-25 was followed by a second display and storm of only slightly less intensity on March 29-30. The first storm began $24 \mathrm{~d}$. $13 \mathrm{~h}$. $45 \mathrm{~m}$., and ended abruptly 25d. 13h., the later phase from 5h. being characterized by unusually large and rapid oscillations. This storm was greater than that of the great aurora of January 25, 1938, the range in declination being more than $150^{\prime}$, and in horizontal force more than $750 \gamma$, being beyond the limits of registration in both elements. It was preceded by definite disturbances of moderate intensity from $20 \mathrm{~h}$. to $23 \mathrm{~h}$. on March 22, and from $20 \mathrm{~h}$. $30 \mathrm{~m}$. on March 23 to $\mathrm{lh}$. on March 24, and was followed by a notable disturbance from $20 \mathrm{~h}$. on March 25 to $3 \mathrm{~h}$. on March 26, the series forming a well-marked sequence at about one day's interval. 